\title{
ENHANCING TECHNOLOGY EDUCATION BY FORMING LINKS WITH INDUSTRY: A NEW ZEALAND CASE STUDY
}

\begin{abstract}
The New Zealand technology curriculum suggests that schools should seek to develop links with industry as a means of providing real-world examples of technology practice. However, if a school is to form links, what form might such links take, and with whom should they be made? The case study research reported here represents an investigation into the perceptions different New Zealand education stakeholders have toward the development of a link between a rural school in a low socioeconomic setting, with a local biotechnology organization. The study found support for the link across all stakeholder groups, but the research findings suggest that addressing cultural issues, especially those of Māori (indigenous New Zealanders), is important. Other factors such as a lack of knowledge and understanding amongst teachers about biotechnology in general and emerging biotechnology industries in particular were identified as potential inhibiting factors. The results suggest that a long-term relationship is desirable, and that open and regular communication between stakeholder groups is essential in the establishment of school-industry links.
\end{abstract}

The recently enacted Technology in the New Zealand Curriculum document suggests, among other things, that schools should seek to develop links with industry as a means of providing real-world examples of technology practice (Ministry of Education (MoE), 1995). However, if a school is to form links, what form might such links take and with whom should they be made? Also, what problems or issues might arise in forming such links? An investigation into the perceptions different groups have toward the development of a link between a school and a particular industry is likely to be helpful in determining the expectations that each group would have, and may serve to highlight any perceived barriers should a link be developed. Consideration of teachers' perceptions, along with the perceptions of others in the school community and workers within industry, suggests that forming school-industry links is not simple and that cultural implications as well as the logistics of developing a link need to be considered.

The research reported in this paper consists of a case study that explored the perceptions different groups have toward the development of a link between a biotechnology industry specializing in transgenics ${ }^{1}$ and a rural school in New Zealand. The findings from this study will likely be of interest to New Zealand and overseas technology teachers, particularly

\footnotetext{
$\star$ Author for correspondence.
} 
those keen to establish links with 'high-tech' industries. The work will also be of interest to teachers of technology in rural areas, low-decile schools (i.e., low socioeconomic setting), and those who teach in schools located in bicultural or multicultural contexts.

This research explores the possibility of developing a link between a rural school (called Rural School) and a local agricultural biotechnology industry (called Tech-Industry) specializing in transgenics to produce pharmaceuticals in the same community. The research investigated the perceptions of three different stakeholder groups: technology teachers at Rural School; employees from Tech-Industry; and other community stakeholders. Specifically the research aims for this project were to understand the educational stakeholders' views about: the desirability of forming a link between Rural School and Tech-Industry; expected purposes, nature and characteristics of a link; intended outcomes; perceived benefits for each of the stakeholders involved in the link; and perceived barriers to developing a link.

\section{BACKGROUND TO THE STUDY}

McCormick, Newey \& Sparkes (1992, p. vii) point out that "technology education is a newcomer to the school curriculum." The New Zealand technology curriculum (MoE, 1995), for example, was produced as a draft document in 1993. A revised and final version was available for schools to use in planning technology education programs from 1999. The technology curriculum replaced the 1986 Forms 1-4 Workshop Craft syllabus for schools as well as elements of the Home Economics syllabus (revoked at the end of 1999). By the time the New Zealand technology curriculum document was finally gazetted in 1999, schools were expected to have technology programs in place for all pupils in Years 1-10.

The technology curriculum indicates a movement toward the preparation of students to participate in technological development in their communities by becoming better informed (knowledgeable), more understanding, and capable of critical debate. Whereas the previous craft-based syllabus in schools placed emphasis on practical capability, the technology curriculum introduced a strand with a critical element. This Technology and Society strand widens the sphere of technology study to acknowledge that: "Technological practice takes place within and is influenced by social contexts" (MoE, 1995, p. 6). This strand thus requires teachers to recognize the underlying values and beliefs in the community in which a unit of work is positioned, to acknowledge that technology is value-laden, and 
to allow the opportunity for an array of perspectives to be presented to students.

Biotechnology is listed in the technology curriculum document as one of the seven areas of technology that schools are expected to offer students. Genetic or biomedical engineering is included with reference to contexts that are considered within this field. Expressly indicated is the expectation that technology education studies will be contextual for students, and that there will be some overlap of technological areas (MoE, 1995). The technology curriculum is organised into three inter-related learning strands: Technological Knowledge and Understanding, Technological Capability and Technology and Society. These three strands are intended to promote technological literacy (MoE, 1995).

According to Jones (1997), technology-literate students should able "to contribute to informed decision-making about technology and to become empowered to be active in response to new technological challenges" (p. 51). There also is a 'cultural purpose' presented in the New Zealand curriculum, and this states that students will

become aware of the diversity of valid ways in which different groups of people respond to technology and to innovation, and appreciate the impacts that technological changes have on different peoples. They develop understanding of the beliefs, values, and traditions of other people and how these influence technological development. (MoE, 1995, p. 7)

Jones (1997) maintains that exploration of the impact of technology on their environment encourages students "to take responsibility for that environment and equips them to cope better with changes caused by technological advance," going on to assert that students should study "the history, growth and future trends of technology as they relate to the protection of world resources and security" (pp. 50-51). The economic purpose is not indicated as solely vocational, but rather it is intended that students will become equipped to "contribute to New Zealand's social and economic development" (MoE, 1995, p. 7).

\section{RELEVANT LITERATURE}

It seems that the literature supports the notion of school-industry links. There is support especially for links between schools and their local industries, which is seen as 'logical' (Careers Service, 1996). Links are promoted by research of successful regional link programs now operating in some communities in New Zealand (Benson, 1991; Careers Service, 1996; City of Manukau Education Trust (COMET), 2002). School links with local industry are seen in the literature as one means of achieving effective teaching and learning within a specific curriculum area (Openshaw, 1991). 
The above literature is concerned with school-industry links in general. There is little in the literature about forming links with modern biotechnology industries such as transgenic industries, although there is some documentation of schools linking with genetic research in a molecular biology laboratory (Careers Service, 1996).

Other relevant reasons for industry to be involved in links with schools reported in the literature are the 'structural' needs for industry. These include "mechanisms for interaction with the general education system to increase the relevance, and improve the appeal, of the curricula" (Christie, 1992, p. 3). Teachers also see potential motivational value for student learning in forming links with industry. This can occur through the use of industry personnel providing relevant learning opportunities for school students, thereby complementing teachers' rather limited knowledge of industry (Owens, 2000).

How we go about including consideration of values in technology education programs is not clearly indicated in the literature, although some authors provide suggestions as to how we might guide students understanding of the complexities of values in society, and how this might impact upon technology education (Asia and the Pacific Programme of Educational Innovation for Development (APEID), 1991). Pacey (1983) classifies values into three contrasting groups: those stressing virtuosity; economic values; and, user or need-oriented values (Wajcman, 1992). Other distinctions are made between scientific/technological values and humanistic values, and analyzing human values further to distinguish between humanistic values upheld universally and values upheld by particular groups (APEID, 1991, p. 18). Values, however, are defined by the culture in which they exist and different cultures bring different contributions to technology education programs which, rather than being problematic, may serve to enrich the curriculum (Jones, 1997) and transfer of technology across cultures (Durie, 1997). Seen in this light, values are considered to be important perspectives in providing "potential for future technologists" (Jones, 1997, p. 58). Jones goes on to state: "The impact of culture and values (both individually and in the community) are central to teaching and learning of technology" (p. 58).

New Zealand, like other countries, has been dominated by what is sometimes labeled Western or European science. In the minds of some authors, there is an uncomfortable relationship between science and the traditional views or values associated with many indigenous cultures (e.g., Durie, 1997). As a consequence, the juxtaposition of traditional cultural values and beliefs with new technologies such as transgenics could prove to be a most compelling reason to initiate a link. Such a link may on the 
one hand provide an opportunity to discuss and critically analyze topical issues, and on the other hand become the biggest obstacle in linking, with all parties, especially teachers, reticent to enter the 'minefield' of values-oriented education. This is a particular issue in New Zealand because of perceived obligations associated with a nation-founding document, the Treaty of Waitangi, from which the Ministry of Education sees a need for taking the views of Māori into account when designing and implementing curricula (MoE, 1993). Durie (1997) points to the importance of recognition of values that guide Māori technological practice and describes how Māori operate within their own traditional technologies. For example, some concepts indicated by Durie might help us to perceive how Māori view other technologies. Concepts such as tapu (i.e., sacred), mauri (life principle, special character), kawa (protocol of dedication) and tikanga (custom) are mentioned and Durie states that:

While Māori do intervene, invent or otherwise make use of the greater environment to serve their needs, within a Māori framework those interventions and inventions must be considered in relation to their total social, environmental and economic cost. (Durie, 1997, p. 43)

Durie (1997) identifies values such as "non-exploitation, replenishment, restricting of waste and respecting the source" seeing them to be inherent in philosophies underlying "all direct engagement with natural resources" (p. 33), and enduring and important to Māori. The recent New Zealand technology curriculum stocktake ${ }^{2}$ points to the difficulty teachers may have reconciling the values of different cultures in a study of emerging technology (such as transgenics). This problem is encapsulated by a teacher who felt that "it is difficult to combine South Pacific traditions with ballooning 'European' technology" (McGee, Jones, Bishop, Cowie, Hill, Miller et al., 2002, p. 148).

It is not clear from the literature how industry might be 'strengthened' or enhanced by links with schools, but there are reports of some specific benefits for industry engaging in school-industry links (Careers Service, 1996). These include: the recruitment of 'up-to-speed' school leavers; the opportunity to use school facilities and services (such as night school classes); mutual professional development through the exchange of ideas between education and industry organizations; the chance to influence the curriculum and communicate skill requirements; the production of training resources for industry by students and teachers; and, student input which is seen as fresh, timely and of high quality (Careers Service, 1996; Hodges $\&$ Coolbear, 1998).

Benson (1991) claims there is mutual suspicion between teachers and industry which he sees as arising from lack of understanding of the other 
potential partner's operation and "based on perceptions, of the character, motives and agenda of the other group" (p. 33). Christie (1992) suggests that suspicion is most likely to arise from the education quarter, seeking to guard their preserve of academic autonomy (see also Education Review Office (ERO), 1996). Some authors consider that criticism from business aimed at the education sector has contributed to the tension between these two groups (Benson, 1991; ERO, 1996). ERO describes this as "a battle between a functionalist or utilitarian view of education and the liberal ideals that have underpinned the historical development of the New Zealand schooling system" (ERO, 1996, p. 8).

Suspicion from the wider school community, who may not have an understanding of industry, may also inhibit moves to form a link. However, some organizations have overcome the latter by employing an independent coordinator to facilitate the link (Careers Service, 1996): furthermore, "negative myths about school-business links" (COMET, 2002, p. 13) are identified as an inhibitor that needs to be addressed through publicity and reports of success.

\section{MeTHODOLOGY}

\section{Theoretical Perspectives}

This inquiry has been conducted within an interpretivist paradigm with a social-constructivist view of learning (Good, Wandersee \& St Julien, 1993). The authors believe that an individual's constructs are influenced by his or her environment and are subject to influence by prior knowledge, peers, learning experiences, social interactions, and context (Tobin, 1993). Such beliefs are personal in nature and as a consequence, mental construction of beliefs represents a personal cognitive process. In spite of this, many authors now feel that previous work has not adequately addressed the sociocultural component of knowledge construction (see, e.g., Wertsch, 1991). In the present work, the researchers wish to develop an understanding of the beliefs about the desirability or otherwise of forming schoolindustry links for the participants in this study. We thus recognize that we need to situate our research findings within the context in which the study was conducted, and as a consequence place emphasis on the social aspect of social-constructivism. To develop our approach with a socialconstructivist framework, we have drawn on current thinking from sociocultural views of learning. Sociocultural views of learning suggest that past research has not paid enough attention to the social mediation of mental construction (Wertsch, 1991). We strove to develop an understanding of 
the context in which this work was situated, and here present a detailed description of the context for each of the three stakeholder groups involved in this work.

\section{Participants Involved in the Study}

Three cohorts of participants contributed to this research project: three teachers of technology (pseudonyms, Scott, Abraham and Jenny), two staff from industry (pseudonyms, Alex and Jo), and three participants from the wider school community (pseudonyms, Robert, William and Lisa). The teachers were seen as the key figures in implementing a link between school and industry. Teachers are generally the ones to initiate a link and the quality of the link depends very much on a teacher's ability to sustain and maintain a good link. Industry is obviously an important group to consider if they are to be the partners in a link with a school, and their expectations as stakeholders are recognized in this research. Parents and other adults in the school community are also identified as stakeholders in the education of young people and their perceptions are therefore considered relevant. The adults consisted of a kaumatua (Māori elder), parents, and a member of the school Board of Trustees (elected representatives responsible for school administration). An attempt was made to keep the three cohorts of participants relatively even in size and yet incorporate and reflect the diversity of perceptions, knowledge and opinions that may be evident in the different groups. Each participant was given a series of questions in advance and subsequently interviewed individually (see below). Interestingly, it became apparent that most of the individual participants had communicated with others in their stakeholder cohort and with colleagues about the topics and about the other groups relevant to the study.

\section{The School, Rural School}

Rural School is a small rural school with a rumaki (full immersion Māori language class). It is a legacy of the 'boomtown' phenomenon based on electricity generation that prompted construction throughout New Zealand during the middle of the 20th century. When the construction projects were completed, the town survived at least in part because of new industries, such as agriculture and forestry. During the 1950s, Rural School enjoyed its status as one of the largest secondary schools in New Zealand. Since then the school roll has reduced to the stage where it was merged with the primary school to become an 'area school' (i.e., Years 1-13). The number of Year-9 to Year-13 pupils has continued to decrease and at the time of the study the number of pupils attending at Year 9-13 levels was 40 out of a total roll of 194 students for Years 1-13. 
Not all local children attend Rural School, many traveling daily to schools in adjoining districts or towns. The exodus of young people from the community to attend secondary schooling in other towns exacerbates the problem of retaining pupils at Rural School. Some $80 \%$ of the staff have taught at the school for five years or more, indicating considerable stability in staffing. Three staff are involved in teaching technology at senior level (i.e., Years 9-13), and all of the seven teachers teaching junior classes incorporate technology into their programs. Rural School is in a low socioeconomic region with high unemployment rate and a high percentage of homes where a government benefit is the main source of income. ${ }^{3}$

\section{The Community}

The community in which Rural School is situated is very different from other areas in New Zealand, with strong Māori representation in the community. This stems from two sources; Māori from original iwi (tribes) surrounding the town, and others from iwi representatives of the migration from a region in the South-East of the North Island as a result of compensation from the Government at the end of the 19th century. This latter representation has become established since the early 20th century when the first major migration occurred to settle the land for farming. The settlement of land by a trust (formed to represent the iwi) coincided with the Government-assisted post-war settlement of land in the same district and the initiation of hydroelectric dam projects along the prominent river in the area. The town currently has a population of approximately 1100 people.

\section{Tech-Industry}

The local biotechnology/transgenics industry involved in this work (i.e., Tech-Industry) consists of a farm specializing in the production of a 'manufacturing flock' of transgenic sheep. Currently, this site is concerned with field trials for the manufacture of pharmaceuticals. Tech-Industry was established as a production unit to cater for a manufacturing flock with the intention of producing an enzyme to be manufactured as a pharmaceutical. This form of 'high tech' biotechnology is heavily reliant on field trials to determine the effectiveness of proteins as pharmaceuticals. The company applies transgenic technology to produce a range of proteins for therapeutic use. The lead product at the New Zealand site of Tech-Industry is a substance that has proven beneficial in the treatment of chronic emphysema (Environment Risk Management Authority (ERMA), 1998). Staffing at the local site has grown from seven employees in the mid-1990s to 17 employees at the time of the study. 


\section{Research Procedures}

For the work reported in this paper, a series of questions were compiled and sent to the participants in advance. There were two purposes of this strategy. One was to allay any fears about the interviews, deemed necessary because of the sensitive nature of the industry involved in this work. The second reason was to alert the participants to what topics would be discussed so they could expand on these in the interviews. The intention here was that the participants would have time to think about the topics and be ready to discuss these topics further, as well as introduce information that they believed might contribute to the research. The participants also prepared written responses to the questions, and these along with the interview transcripts formed the data corpus for the study.

Before distribution to the participants, the questions and interview protocol were evaluated by two other people representative of each stakeholder group, but with no contractual interest in the study. Further scrutiny was provided by colleagues who volunteered to trial the questions relevant to teachers; by a middle management person in another industry located in the community; by a manager of a small business who trialed the section pertinent to industry; and by parents (other than those who were to be participants) who tried out the section intended for the third group of participants (i.e., representatives from the school community). All of these three groups provided helpful suggestions for clarifying the intention of questions, justifying the inclusion of certain questions, trying to eliminate ambiguity, ensuring there were no offensive or sensitive questions, and designing the questions so that they were easy for participants to understand and complete.

The interviews expanded on responses to the questions (see above) and explored areas not covered. There was the opportunity to clarify interpretation of the questions as well as the participant responses. Interviewees could also contribute to the areas covered by the interview and some offered relevant information that the researchers had not considered. The participants contributed to the knowledge base that informed the research in a way that acknowledges the contextual nature of the research. The dynamics of the interview technique and the qualitative nature of the method meant that the interviewer, together with the interviewee, was able to explore the diverse situations of the individual participants. The interviews ranged from 30 to 50 minutes in duration and were captured on audiotape. The dynamic nature of talk (Powney \& Watts, 1987) is lost somewhat in transcribing, but the transcripts enabled the interviews to be validated by both the interviewee and the interviewer. 


\section{Case Study Design}

The research reported here is a case study because this approach can penetrate situations in ways that are not always susceptible to numerical analysis (Cohen, Manion \& Morrison, 2000). One of the strengths of a case stu$\mathrm{dy}$ is that it can observe effects in real contexts and recognize that context is a powerful factor of both causes and effects (Yin, 1994). Case study is effective for investigating and reporting on the complex, dynamic and unfolding interactions of events and relationships in a unique occurrence. It is able to capture unique features that may hold the key to understanding the situation that could be lost in larger scale data, such as a survey. Case study also has the advantage of being strong on reality and can incorporate unanticipated events and uncontrolled variables. According to Guba \& Lincoln (1989) the inclusion of more, rather than less detail, is the hallmark of effective case studies. The case study reported here is what is refereed to as an intrinsic case study; a case study in which one seeks a better understanding of this particular case. Such case studies are undertaken primarily because the case itself is of interest, not because it represents other cases or because it illustrates a particular trait or problem (Merriam, 1988).

A disadvantage of the case study is that it is prone to problems of researcher bias and it is not easily open to cross-checking, hence it may be selective and subjective (Nisbett $\&$ Watt, 1984). In order to reduce the likelihood of investigator bias the researchers utilized a variety of tools to enhance the trustworthiness of this study in accord with the recommendations of Guba \& Lincoln (1989). These were: negative case analysis, the use of disinterested peers, and the provision of an appropriate audit trail to provide transparency in the conduct of this research. Likewise, in accord with an interpretive approach, the research findings reported here are not necessarily directly generalizable to other settings. An alternative, and that is applicable here, is the notion of transferability (Guba \& Lincoln, 1989) in which the reader evaluates the significance of the findings in his or her own educational context. The provision of descriptive findings along with details of the participants (see above) is intended to facilitate this process (Merriam, 1988; Peshkin, 1993).

\section{RESEARCH FINDINGS}

The research findings are reported here in relation to the research aims: the desirability of forming a link between Rural School and Tech-Industry; expected purposes, nature and characteristics of a link; intended outcomes; perceived benefits for each of the stakeholders involved in the link; and, 
perceived barriers to developing a link. The respondents' views as to each of these issues are now described in turn.

\section{TEACHERs' PERCEPTIONS}

\section{Should there be a Link between Tech-Industry and Rural School?}

The teachers were unanimously of the view that Rural School should form links with local industries, but two were more cautious when interviewed about the possibility of forming a link with this particular industry. Only one of the teachers, Scott, was enthusiastic about forming a link with TechIndustry, remarking: "I would encourage any link," but Abraham was more hesitant about promoting the development of a link and specified that before Rural School engaged in a link Tech-Industry would need to declare their motives, commenting that "I want to know their agenda."

Reasons and Purpose for Establishing a Link between Tech-Industry and Rural School

The most obvious reason for forming a link, according to the teachers, was the opportunity to link with an industry that was in close proximity to the school. One respondent believed that the school should use local community resources and saw Tech-Industry as a valuable resource that Rural School could utilize. Scott commented: "They are local and the school has a responsibility to tap into community resources."

The need to provide the public with an accurate representation of TechIndustry was seen as an important reason for establishing a link. Scott, for example, thought that a link between Rural School and Tech-Industry would go some way toward overcoming ignorance about this local industry and correcting misinformation: "There is so much ignorance and misinformation, the very reason for a link would be to clear up misinformation." Scott pointed to the significance of cultural issues in this specific educational context, in particular "the fact that cloning and genetic modification happens to be a strong issue with Māori."

Likewise, the teachers commented that a link would "enhance the curriculum" and thus enable teachers to complement their "own knowledge base." This was deemed desirable because "teachers are sometimes limited in their knowledge of technological fields. The experts know all about biotechnology." Another purpose identified was to show students how schooling was linked and relevant to working life: "For education to have any relevance at all it has to be linked to the job. These kids have to earn money and that's where industry comes in." 


\section{Forming a Link between Tech-Industry and Rural School}

The teachers considered that a variety of individuals might be responsible for initiating a link between Rural School and Tech-Industry: teachers, industry, an industry liaison person, a school liaison person, or an independent facilitator. The teachers highlighted the importance of communication between the parties, someone taking responsibility for initiating a link, the perceived character of people facilitating the link and the involvement of other individuals and groups as crucial. However, teachers were seen as the most likely people to initiate a link, and according to Jenny: "It would probably be us ... we don't mind taking the first step," but onus was also placed on Tech-Industry by other teachers: "I'd like to see (Tech-Industry) take the initiative," and an industry liaison person was seen as potentially appropriate: "They need to send someone out to our school to say 'oh, I can help you here.'" The reason it was thought TechIndustry may wish to establish a link and take the initiative was essentially public relations, with Scott commenting: "By having this kind of liaison and representation, it can help to clear some of those things up." The idea of using an outside facilitator was mooted but generally dismissed on the basis of cost, potentially "suspect motives," and past bad experiences of using facilitators. In any event, communication was seen as vital: "What would have to happen is a lot of two-way communication." Finally, given the sensitive nature of Tech-Industry's business, the teachers felt that community-wide consultation would be essential, especially with Māori, as Scott commented:

I would go to (name) if I wanted a radical Māori perception, because that's how I see him, but then I would also go to someone like (name), who's a kaumatua (Māori elder) here and I would get his 'not-so-radical,' more balanced view. I would look at key Māori figures that represent quite a wide spectrum.

\section{Types of Links and Characteristics of an Effective Link between Tech-Industry and Rural School}

The types of links mentioned throughout the responses to the written questions and interviews indicate that the teachers perceive that a link might include: sponsorship, units of work involving school visits, site visits and resource materials from industry, and work placements for students. The teachers commented that any link should include what they saw as key characteristics of an effective link between Rural School and Tech-Industry. The teachers felt that any effective link would need to be planned, purposeful and sustained. Scott stressed the sustainability of the link: "I'd look for a more planned, purposeful, sustained link. Something that's not just a one-off site visit." 
The teachers felt that both parties should derive benefit from a link and that this would likely contribute to the sustainability of the link. However, the teachers were honest in declaring they would seek to meet the needs of themselves and their students first in deriving benefit from the link. Scott, for example, maintained that teachers need to perceive some benefit for themselves and/or their students before they will engage in a link. As mentioned above, communication and appropriate motives were also seen as crucial.

\section{Benefits and Barriers of a Link between Tech-Industry and Rural School}

The teachers saw potential benefits for all stakeholder groups Rural-School, Tech-Industry and the wider community. The school would likely benefit from enhanced curriculum, showing students that schoolwork and learning is vocationally relevant (see above), providing 'real' learning experiences, and, additionally, keeping students up-to-date with topical issues in fields like biotechnology. This latter function was seen as the key potential benefit for Rural School, with Scott commenting: "That way what industry is discovering today, schools will be doing today too instead of discovering tomorrow," and adding "because technology is such a new field, it is the cutting face of education, it is where education changes so much."

The teachers saw potential benefit for Tech-Industry in the good publicity the local industry might receive and the chance to present their side of the story:

Let's assume that this program is up and running and you've got this liaison relationship developing, you've suddenly got trust, because you've got communication that you didn't have before and you've got community backing and community support so if there are any serious issues or questions you've got a community that feels a lot safer and more comfortable. There's also that whole issue of transparency. If a company's involved in a school, then there's an ongoing relationship. They look a hang of a lot more transparent than a closed, darkened-windowed company that's keeping quiet about certain issues. (Scott)

It was also considered that Tech-Industry might be able to tap into "bright young people" as future employees.

Finally, the teachers also saw some potential benefits for the local community, thinking that locals, especially parents, would benefit from a deeper understanding of a biotechnology company of this nature: "If a parent becomes a party to the relationship (they) can benefit by improving their own knowledge base."

Perceived barriers were school-based, mostly to do with perennial issues such as funding "obtaining money from parents for something like this," and time commitments "it is actually committing the time and energy, it's sustaining the development of something like this," as well as 
"potential misbehavior of pupils" on, say, industry visits. But the main barrier was seen to be a lack of long-term commitment on both sides: "Lack of initiative, things sound good when you talk about them, but they just get talked about." Industry barriers were related to regulatory control, being "out of bounds," and "communication issues."

\section{INDUSTRY PERCEPTIONS}

Should there be a Link between Tech-Industry and Rural School?

Both the industry participants Alex and Jo felt there should be a link established between Tech-Industry and Rural School, and saw good reasons for such a link.

Reasons and Purpose for Establishing a Link between Tech-Industry and Rural School

First was an awareness of technology and Jo believed exposing people to the technology within the industry was important so that people can make informed judgments: "They can't accept or reject what they don't know." Job potential also surfaced with Alex commenting that revealing TechIndustry would show locals what opportunities existed for employment in a sector that many locals, particularly Māori, might have not considered accessible to them: "Highlight the skills needed to work at Tech-Industry. Anybody with nous (i.e., common sense) can achieve by themselves and get a job here."

Some of the purposes for a link are alluded to in the reasons given above by the industry participants. Other perceived purposes of a link included the opportunity for Tech-Industry to "showcase" its business and, again, educating local students about potential vocations surfaced as a predominant theme, with Jo commenting: "I personally believe children need to be made aware of the huge scope of careers available ... local children in rural areas may only be exposed to a limited number of careers due to isolation." The other main theme was education and correcting misinformation, with Jo's perception that a link might create an awareness of "technology uses and benefits to the community." This, Jo felt, could only be seen as credible if presented in a "balanced" manner. Jo also saw potential for a link to be used to develop critical thinking by stimulating critical debate, even with young children, using such ideas as: "What would be the repercussions of technologies now or what if we could have something that could do this or that?" 
Forming a Link between Tech-Industry and Rural School

The industry people were divided about the use of a facilitator to initiate and operate a link between school and industry, but, like the teachers, felt that open and honest communication was essential. Jo felt that "a facilitator would be good idea," but Alex had some reservations asking "would you have to educate the facilitator?" The idea of using a facilitator, it seems, stemmed from the usual concern with time/resource commitments for both parties. The industry staff also highlighted the need for someone to take the initiative, but, unlike the teachers, they felt that a local community person may be more suitable than a facilitator from elsewhere: "You'd be better to keep it as a local thing."

\section{Characteristics of an Effective Link between Tech-Industry and Rural School}

Both the industry workers anticipated that a link would require an initial planning period where the parties involved met to decide what they were trying to achieve by forming a link, and to determine what the goals and outcomes would be. Jo sought a consensual link that considered the needs of the parties involved, and felt that consideration of the school curriculum was important: "If just one side, for example, like if we just wanted to just go on about how wonderful gene technology was or something, I mean that is not an even balanced thing and not everyone would be in agreement. So it needs to be fitted in with the curriculum."

Alex also stressed the importance of a consultative, inclusive, approach: "Done the correct way, open channels, correct consultation ... you've got to have someone (i.e., from Tech-Industry) involved in the initial planning." The inclusiveness extended to ensuring that parents and the school community were informed, "if (Rural School) say said 'next week we're having (Tech-Industry) come to the school' then if people wanted to come themselves you could do that," but respecting any wish to be excluded: "some people don't want their kids being taught about stuff like that and so they'll withdraw their kids."

Both of the industry workers saw it as essential that any content of a link be negotiated by all stakeholders and perceived the unique nature of Tech-Industry (i.e., a farm-based biotechnology industry) as providing a broad range of educational opportunities. Jo's concept of an educational program was that the program would be incremental in nature, and pitched at a level appropriate for the students:

They're only going to hear those bits that are relevant to them. There is only so much they're going to take in that's going to answer what questions they've got. Then they'll have more questions when they're older about different things ... will add on to what they've 
already got. But they can't take on any more than they are ready for. All that technical stuff.

Jo went on to talk about possible topics such as "animal husbandry, office management and record-keeping," pointing out that "we have training courses where people come in and train us on things like riding (motorcycles) on hills and stuff like that." The Tech-Industry staff felt that a link would be more suitable for senior students because their business was seen by Jo as "advanced stuff, there is a lot more issues," and Alex commented that "anyone 15 years and under, I don't think they've got the comprehension to really grasp what's actually going on." But they did feel that classroom or site visits may be of some benefit, even for younger participants if carefully managed.

Mode of delivery for a link potentially included school visits, site visits, audio-visual production and resource boxes. However, because of regulations imposed on Tech-Industry by controlling authorities, such as the Ministry of Agriculture and Fisheries (MAF), and the protection of the product to be produced, the workers did not think on-site visits would be feasible. Instead there were other ways in which the farm operation could be presented to students. Audio-visual recording was one method that the industry workers considered could be employed, and Alex considered the possibility of students producing a documentary-type video to represent the farm operation: "If (Tech-Industry) was receptive to it, they could do a video of it all themselves and say, 'hey, this is the operation. This is what we do, day in and day out.' That should show basic jobs."

These respondents envisaged that the intended outcome of this activity would be multifarious; producing the video would be a learning experience in itself (e.g., students would be learning about the farm operation as well as the process of producing a video), and the video could be used as a resource in other classrooms or schools to inform other people about the farm operation. The industry workers did realize that this type of exercise would entail at least one student going on site to film, but Alex remembered that Tech-Industry "have had individuals work (on-site) on a holiday period." Alternatively, respondents suggested the initial learning experience of the students could produce a booklet or other forms of resources to be used by other children.

Resource kits were seen as a possibility for sharing information about the industry. Other industries in the area were given as examples of companies that produce resources suitable for schools to use. 
Benefits and Barriers of a Link between Tech-Industry and Rural School

The workers from Tech-Industry saw all three parties potentially benefiting from a school-industry link: Tech-Industry, the Rural School and the community. The potential benefits for Rural School were much the same as described by the teachers, "enhanced learning for students," and "encouraging interest in technology," whereas Tech-Industry was seen as likely to benefit from "building a better relationship with the community." Again the barriers were similar to those identified by the teachers: restrictions to on-site access (see above), and potential parental concerns. Jo said "I just wonder if some parents felt really strongly about it, whether they might say we don't want Tech-Industry coming to our school."

\section{COMMUnity PERCEPTIONS}

Should there be a Link between Tech-Industry and Rural School?

The community group's support for establishing a link between Rural School and Tech-Industry was similar to that shown by the other two cohorts of participants. Robert commented that "they could build a relationship" and Lisa supported this saying "I think it would be a positive move and I can't actually see anything negative about it." The respondents felt that the link should be expanded to include other industries, William commented "there are a lot of industries out there and I'd like to see Rural School link with all of them" and Lisa agreed that "I think it could benefit the school and industry as well."

Reasons and Purpose for Establishing a Link between Tech-Industry and Rural School

The reasons proffered for forming school-industry links were similar to those provided by the participants from Rural School and Tech-Industry: knowledge of this type of industry, knowledge of potential occupations, enhanced student motivation for learning, knowledge of local industry, enhanced curriculum and so forth. Robert felt links with Tech-Industry could enhance the curriculum by complementing what was learned at school: "Having the link there would be a practical way of carrying through on to some of the areas that are covered at school." Lisa said that the link might "aid the school in developing education in a way that might be suited to employment in the future," going on to comment that "basically for careers is, I think, the most important reason for having those links." However, some other interesting issues were raised, and these were contextual to the 
rural community in which Rural School and Tech-Industry is located. For example, William pointed to his perception of low work ethic in the region: "A work ethic is hard to teach (i.e., in school). If they haven't had a work ethic around them growing up, it's pretty hard to instill that into them."

\section{Forming a Link between Tech-Industry and Rural School}

Forming a link was seen by people in the community to be the school's responsibility, and this was related to the curriculum objectives: "The teachers would be the more obvious ones (to initiate a link), in that they would, probably, be more aware of the outcomes that they have in mind and, so, presumably, would be able to look at the industry and see what areas applied."

Robert felt that it was also possible that Tech-Industry might initiate the link if administration within the local industry had a vision of establishing a link with Rural School and if someone within the local industry had experience of establishing such links. He felt that such a person would be ideal to initiate the link: "If the administration of the industry had some ideas that they wanted to, or they felt they could do with the school, equally, then they would have a goal, a vision that they would promote and manage, so if they have that vision there's nothing wrong with (industry initiating the link)." Again, all of the respondents felt communication and community involvement would be essential, but not until Rural School and Tech-Industry had established a need to develop a link. Robert said:

I don't see in the initial stages that there is a need to consult beyond the school. I see it as part of the school working on an activity that is being promoted using an outside resource. But it's still working within the school, working on it and I don't really know that anyone else needs to be involved.

\section{Characteristics of an Effective Link between Tech-Industry and Rural} School

When the participants in this group contemplated a supposed link between Rural School and Tech-Industry, there appeared less tangible aspects contributing to the nature of the link. These characteristics were to do with the way the different groups might communicate, consult, consider, negotiate, and arrive at a mutual understanding of what a link would constitute.

So, for example, the respondents considered communication an important part consultation as described above. The major theme to emerge here was that consultation would need to take into account cultural factors, especially Māori values and beliefs about such a controversial industry. Justification for including local $i w i$ in the consultation process was propounded by Lisa explaining that iwi are "part of the community," and that 
"with any school project, iwi should be informed." Including local iwi in the consultation phase was considered to be important because of the perceived nature of Tech-Industry: "It's such an intense, scientific, modern industry there may be some people who have issues about (Tech-Industry) and just to make them aware, rather than have them come back and say they weren't informed."

The respondents indicated that the consideration of traditional culture needed to be addressed at an early stage and was an important reason for consulting with the local Māori community. Responses from this group indicate complexity in reconciling the values of tikanga Māori (traditional cultural beliefs) with the intentions of the transgenic activity of TechIndustry. Reference to the importance of tikanga Māori proliferated through the responses. William, for example, expressed the loss of knowledge about traditional cultural beliefs for Māori people of his generation. He went on to explain how Maori people in previous generations had been encouraged to adopt European culture with the consequent depletion of knowledge of tikanga Māori within Māori communities in subsequent generations. William described how the generation representing parents of students are now attempting to recover knowledge of tikanga Māori relevant to their $i w i$ and are well aware of gaps in their own knowledge. He suggested that an awareness of incomplete knowledge, coupled with a desire to recapture and adhere to traditional tikanga Māori, has led to a tentative approach to the acceptance of new technologies that may or may not encroach on the sanctity of tikanga Mäori.

As previously stated, participants in this group recognized the need for a partnership arrangement in order to engage and retain Tech-Industry's interest in the link. However, these respondents also perceived the link as likely to benefit Rural School more than Tech-Industry. Nevertheless, the group did give some consideration to what Rural School could offer Tech-Industry in a partnership between the two organizations. The school facilities as a venue for professional development and the workshops were considered to be assets Rural School could share with Tech-Industry, with Lisa saying "the school has got some very good facilities that could be utilized," and William commenting, "perhaps, say (Tech-Industry) looking at some sort of venue to up-skill their own persons, or professional development of their people."

\section{Benefits and Barriers of a Link between Tech-Industry and Rural School}

These respondents did not distinguish between benefit for any specific group or cause; rather, they saw each of the stakeholders benefiting from a common outcome. An example of this is the vocational benefits and pos- 
sibility of future employment at the local site expressed by the community participants. To illustrate, the participants perceived this outcome as benefiting a number of groups: any individuals (including students) who might successfully gain employment by acquiring the insight and knowledge needed; the industry (by fulfilling the need for employees, preferably from the local community, with the appropriate knowledge, skills and attitude); and the community (by fulfilling the need to raise level of employment for young people retained in the community).

Nonetheless, the main beneficiary was perceived to be the school, as seen in Robert's comment that "I believe the school would benefit more than industry." This, it seems, stems from a notion that the school had most to gain in terms of the reasons given above, namely, enhanced student motivation, curriculum, and so on. Other potential benefits included the possibility of Tech-Industry providing student scholarships. Tech-Industry was seen to benefit from increased profile and public relations "making people aware of what the industry is about," and "it would be a good promotional exercise, perceptions of Tech-Industry helping the community," as well as enhancing the local "work ethic" resulting in the potential to tap into "a ready and willing local work pool." Community benefits suggested included perceived employment opportunities and "raising people's aspirations ... if that happens, the spin-off for the community would be better attitudes to learning and goal-seeking than people have at the present."

Perceived barriers identified included confidentiality, security and time. Participants were aware of confidentiality and security issues surrounding the core business of Tech-Industry, but were unsure of how this might impact on a link. As Robert said: "I don't know to what degree the work that happens at (Tech-Industry) . . . is of high security and needs to be kept under wraps." Time was considered an issue for both the school and the local industry: "I don't know that there is time as far as timetables are concerned," and "there is the time of people who have to leave their normal tasks to supervise or liaise with the school." Linking with the school curriculum was also identified as a potential barrier for the teachers: "It depends on the focus of the school and the kind of technology curriculum they want to focus on." Finally, misinformation or misunderstanding about the core business of Tech-Industry was thought to be potentially off-putting:

The way schools are set up now ... the community and the parents of the students within the school are supposed to be more active and they have a right to say anything and if they have got an 'anti' feeling towards this industry and it could be through this misinformation or misconception of exactly what they're doing or why they're doing it. They could actually stop a proposed link. 


\section{CONCLUSIONS}

Curriculum documents often recommend schools engage in off-site learning experiences in order to make science and technology 'alive' for students by means of authentic learning experiences. The research reported in the study sought to investigate the factors of such links. The aims for the research related to forming a link between a small rural school in a low socioeconomic area and a local high-tech biotechnology industry. The researchers sought to understand stakeholder perceptions of the desirability, purposes, nature and characteristics of a school-industry link; intended outcomes; perceived benefits for each of the stakeholders involved in the link; and, perceived barriers to developing a link. In doing so the authors made no prior assumptions about the desirability or otherwise of forming any link. Indeed, given the sensitive nature of the industry involved in this study (i.e., one involved in 'cutting-edge' and somewhat controversial technology), there were, in our view, potential concerns about forming school-industry links, and some of these emerged in the study.

The research reported here suggests that the three potential stakeholder groups (teachers, the local industry staff and the community members) all see some advantages in the formation of a school-industry link between Rural School and Tech-Industry. The advantages were common across the stakeholder groups and included: enhanced curriculum, enhanced student motivation, better understanding of a novel and 'high tech' industry, and demonstration of vocational opportunities. In particular, the stakeholders pointed to the motivational impact of school-industry links, as well as the notion of an enhanced curriculum. Even industry was seen to potentially benefit from a link including access to school facilities/expertise mooted by the community group, and the notion of school-leavers as a source of staff for Tech-Industry.

A few barriers to school-industry links were identified. These were concerned with resource and logistics (e.g., funding, time) and some security and safety issues. Apprehension was identified as another factor that could impact on the formation of a link. The latter concern was only found in the non-industry cohorts and appeared to arise from strongly held values and beliefs and/or apprehension about the core business of the industry. This was further complicated by lack of knowledge (within these two nonindustry groups) about the transgenic industry. An aversion to, or suspicion of, the industry was indicated as a possible barrier that may exist within the school and community. This concern with suspicion was raised by the teachers in particular, but it is worthwhile to note Tech-Industry staff were aware of this potential. Interestingly, the cohort that might have been most 
suspicious, the community including Māori, were less suspicious about Tech-Industry's motives. There were certainly some concerns expressed, but the physical location of Tech-Industry seems to have overcome this in some way. This is interesting given the potential conflict between Māori values and the core business of Tech-Industry. It also seems likely that the vocational opportunities afforded by Tech-Industry in a low socioeconomic area might mitigate against suspicion, and potential employment may be the overriding factor. Overall, the stakeholders were committed to the formation of school-industry links and felt that such barriers would be readily overcome if a specific individual took initiative, this most likely being a teacher.

The literature and the New Zealand technology curriculum stress the importance of education beyond simple accumulation of content knowledge, and suggest that an appropriate technology curriculum (i.e., as implemented, not just prescribed) should include values and the 'human' side of technology. Aspects of these issues emerged from the research findings reported in this work, and there were some indications of features of relevance for values, for example, the notion of school-industry links potentially instilling a good work ethic in local youth, militating somewhat against the high level of unemployment in the region. Likewise the MoE, and science and technology education literature, emphasize the relationship between cultural values and views, and technology. Features of this emerged in the study with all stakeholder groups pointing to issues in school-industry links that involved potential cultural conflicts especially with Māori. Interestingly, this did not appear to be particularly off-putting. Indeed the participants simply acknowledge this as a potential issue, but they clearly feel that as long as the individuals involved in the development of any school-industry link were cognizant of the issues, then the potential conflict need not inhibit such a link. In fact, the common theme to emerge is that the potential benefits for all three stakeholder groups were such that they outweighed any potential problems.

Despite Farmer's (1997) assertion that "biotechnology is too important to be left in limbo" (p. 173), and the constant affirmation of the importance of biotechnology to the New Zealand economy espoused in the media, a 'stocktake' of the technology curriculum in 2002 reveals biotechnology was the least taught area of the technology curriculum in secondary schools (McGee et al., 2002). Also worth noting is that teachers of technology reported that biotechnology was one of the most difficult areas to provide technological experiences for students (McGee et al., 2002). In light of this, the present work clearly points to advantages in establishing schoolindustry links. In other words, the notion of school-industry links of the 
nature described here will, at least in the minds of these participants, serve to enhance the technology curriculum. Evidence for this assertion comes from the fact that the teachers feel a need for industry expertise and the gambit of teaching and learning experiences applicable to the technology curriculum suggested as part of any proposed link between Rural School and Tech-Industry.

In some studies it is reported that students receive "educational benefits" (COMET, 2002, p. 7), but these educational benefits are not necessarily linked to the curriculum. Students also apparently gain increased access to job opportunities (COMET, 2002) and this points to benefits in terms of vocational education. Furthermore, schools report benefits in terms of student knowledge of the workplace and student experience in the workplace (COMET, 2002). Generic benefits for students, again not aligned to a particular curriculum area, include "motivation, confidence and increased ability to study" (Hodges \& Coolbear, 1998, p. 6). This also is borne out in the present work, with the education stakeholders pointing to similar themes in terms of advantages for students.

According to the literature, a lack of effective communication between parties can contribute to failure in establishing an effective link. Inability, or omitting, to articulate the desired outcomes intended by either party can result in the collapse of a link, no matter how well-funded the project nor how energetic the participants (Earl, 2002). The importance of honest communication is also indicated by Benson (1991) and is considered to be essential in the establishment of a link. Without openness, one or other of the parties can become suspicious of the other's motives, prompting another barrier to the development of a link (Benson, 1991). The present work clearly identified open communication as a major issue, consistent with the literature.

\section{IMPLICATIONS}

It is plain from these findings that goodwill is essential in the formation of any school-industry link. The participants clearly felt that all parties need to see potential benefits for themselves, but also for the other education stakeholders involved in any partnership. Part of this was, as mentioned by the teachers, an 'up-front' attitude in which each party states what they expect and want to gain from school-industry links. This leads to the second important implication: clear, open and regular communication between all parties is essential. All parties were adamant that high-level management involvement also is important, so that all parties see the establishment of school-industry links as supported by top management (at the school 
and industry alike). Finally, as reported in the literature, the formation of school-industry links involves substantial commitment of resources (time and physical) and hence there is little lasting value in short-term relationships: all parties need to see the capacity to be involved in a long-term relationship and to commit themselves to such partnership.

\section{NOTES}

\footnotetext{
${ }^{1}$ A biotechnology procedure in which genes are transferred from one species to another for a specific purpose, e.g., to overcome deficiencies from an inherited disorder.

2 The New Zealand curriculum 'stocktake' is a Ministry funded investigation of teachers' perceptions of changes in classroom practice after the enactment of the curriculum documents instituted in the mid-1990s.

${ }^{3}$ A community profile shows $53 \%$ of the population in this community receive a benefit and $73 \%$ of those over 15 years old receive a benefit.
}

\section{REFERENCES}

Asia and the Pacific Programme of Educational Innovation for Development (APEID) (1991). Values and ethics and the science and technology curriculum. Bangkok, Thailand: UNESCO.

Bellamy, R. (2001, Friday 5, October). Our future depends on GM technology. NZ Herald, p. A13.

Benson, S. (1991). Science and technology school industry links. Wellington, New Zealand: Ministry of Research, Science and Technology.

Careers Service (1996). Growing partnerships. Wellington, New Zealand: The Careers Service.

Christie, R. (1992, February). Address by R.G.M. Christie, Chief Executive, New Zealand Trade Development Board. Paper presented at Education for Enterprise Conference. Wellington, New Zealand: Ministry of Education.

City of Manukau Education Trust (COMET) (2002). Business and schools in Manukau. Manukau City, New Zealand: City of Manukau Education Trust.

Cohen, L., Manion, L. \& Morrison, K. (2000). Research methods in education, 5th edn. London: Routledge-Falmer.

Durie, A. (1997). Technology and Māori. In J. Burns (Ed.), Technology in the New Zealand curriculum (pp. 31-45). Palmerston North: Dunmore.

Earl, K. (2002). Curriculum innovation in a New Zealand secondary school: Identification of enablers and inhibitors. Unpublished MEd thesis, University of Waikato, Hamilton, New Zealand.

Education Review Office (ERO) (1996). School-business links. Education evaluation reports. Wellington, New Zealand.

Environment Risk Management Authority (ERMA) (1998, November). Nga Kaihautu Tikanga Taiao. Report to the Environmental Risk Management Authority. ApplicationsGMF980001. 
Farmer, B. (1997). Biotechnology: Bugs, booze and bread or clones, cultures and contamination? In J. Burns (Ed.), Technology in the New Zealand curriculum - perspectives on practice (pp. 173-191). Palmerston North, New Zealand: Dunmore.

Good, R.G., Wandersee, J.H. \& St Julien, J. (1993). Cautionary notes on the appeal of the new 'ism' (constructivism) in science education. In K. Tobin (Ed.), The practice of constructivism in science education (pp. 71-87). Hillsdale, NJ: Lawrence Erlbaum.

Guba, E.G. \& Lincoln, Y.S. (1989). Fourth generation evaluation. Newbury Park, CA: Sage.

Hodges, D. \& Coolbear, P. (1998). Developing a cooperative education programme in New Zealand: An outline guide. Auckland, New Zealand: New Zealand Association for Cooperative Education.

Jones, A. (1997). Technology education in the New Zealand curriculum. In J. Burns (Ed.), Technology in the New Zealand curriculum: Perspectives on practice (pp. 46-59). Palmerston North, New Zealand: Dunmore.

McCormick, R., Newey, C. \& Sparkes, J. (1992). Introduction: In search of technology. In R. McCormick, C. Newey \& J. Sparkes (Eds.), Technology for technology education (pp. vii-viii). Wokingham, England: Addison-Wesley.

McGee, C., Jones, A., Bishop, R., Cowie, B., Hill, M., Miller, T., Harlow, A., Oliver, D., Tiakiwi, S. \& MacKenzie, K. (2002). Teachers' experiences in curriculum implementation: General curriculum, mathematics and technology. Hamilton, New Zealand: University of Waikato.

Merriam, S.B. (1988). Case study research in education. San Francisco: Jossey-Bass.

Ministry of Education (MoE) (1992). Mathematics in the New Zealand curriculum. Wellington, New Zealand: Learning Media.

Ministry of Education (MoE) (1993). The New Zealand curriculum framework. Wellington, New Zealand: Government Printer.

Ministry of Education (MoE) (1995). Technology in the New Zealand curriculum. Wellington, New Zealand: Learning Media.

Nisbet, J. \& Watt, J. (1984). Case study. In J. Bell, T. Bush, A. Fox, J. Goodey \& S. Goulding (Eds.), Conducting small-scale investigations in educational management (pp. 79-92). London: Harper and Row.

Openshaw, R. (1991). Schooling in the 40s and 50s: An oral history. Palmerston North, New Zealand: Educational Research and Development Centre.

Owens, K. (2000). Scientists and engineers in the middle school classroom. The Clearing House, 73(3), 150-152.

Pacey (1983). The culture of technology. Oxford: Basil Blackwell.

Peshkin, A. (1993). The goodness of qualitative research. Educational Researcher, 22(2), 24-30.

Powney, J. \& Watts, M. (1987). Interviewing in educational research. London: Routledge.

Tobin, K. (Ed.). (1993). The practice of constructivism in science education. Hillsdale, NJ: Lawrence Erlbaum.

Wajcman, J. (1992). Feminist critiques of science and technology. In R. McCormick, C. Newey \& J. Sparkes (Eds.), Technology for technology education (pp. vii-viii). Wokingham, England: Addison-Wesley.

Wertsch, J.V. (1991). A sociocultural approach to socially shared cognition. In L.B. Resnick, J.M. Levine \& S.D. Teasly (Eds.), Perspectives on socially shared cognition (pp. 85-100). Washington, DC: American Psychological Association.

Yin, R. (1994). Case study research: Design and methods (2nd ed). Thousand Oaks, CA: Sage. 
Centre for Science and Technology Education Research,

University of Waikato,

Private Bag 3105, Hamilton,

New Zealand

E-mail:r.coll@waikato.ac.nz. 